\title{
Evaluation of Innovative Technologies in Conditions of the Digital Economics
}

\author{
Victoria Prokhorova, Roman Korzh, Oleksandra Mrykhina, Orest Koleshchuk, Tamara \\ Mirkunova
}

\begin{abstract}
The article outlines the prospects and challenges of digitalization of the world economics, which led to the revision of the current paradigm of economic development of the world. Considering the fact that digital technologies are both a market and a vehicle for the emergence and development of new markets, they have actualized the importance of market phenomena and effects (convergence, spillover effect, diffusion of technologies, etc.), which have a colossal influence on the economic evaluation, transfer, and commercialization of innovations. In this regard, one of the important scientific and practical tasks for economists is to develop a methodology for the evaluation of innovative technologies, which would take into account the modern features of digitalization and would increase the competitive position of technologies.
\end{abstract}

The purpose of this study is to substantiate the method of evaluation the cost of innovative technologies in the digital economics. The object of the work is the process of assessing the cost of innovative technologies, the subject - theoretical, methodological and applied foundations of evaluation of innovative technologies in conditions of the digital economics.

The article substantiates the method of estimating the cost of innovative technologies in the framework of a comparative valuation approach. The peculiarity of the author's method is the matrix structure, which contributes to the flexibility of taking into account and/or adjustment of factors affecting the market environment on innovative technology at a particular time. The proposed method enables us to increase the efficiency of pricing and can be used as a basis for justifying the pricing strategy for innovative technologies, making management decisions regarding their market development in the digital economics, etc. The development makes it possible to adjust the price of innovative technology, in accordance with the inherent values of the influence of economic factors on it. The method is tested on the example of enterprises in the field of industrial electronics.

Keywords: Comparative Valuation Approach, Digital Economics, Innovative Technology, Evaluation Method.

\section{INTRODUCTION}

The fourth industrial revolution, defined by the digitalization of almost all spheres of human activity and the

Revised Version Manuscript Received on October 15, 2019.

Victoria Prokhorova, the Department of Economics and Activities of Economic Entities, Ukrainian Engineering and Pedagogical Academy, Kharkiv, Ukraine. Email: vkprohkorova@gmail.com

Roman Korzh, the Departmen $f$ Electronics and Information Technology, Lviv Polytechnic National University, Lviv, Ukraine. Email: college@lpnu.ua

Oleksandra Mrykhina*, the Department of Business Economics and Investments, Lviv Polytechnic National University, Lviv, Ukraine. Email: oleksandramrykhina@gmail.com

Orest Koleshchuk, the Department of Business Economics and Investments, Lviv Polytechnic National University, Lviv, Ukraine. Email: orest.y.koleshchuk@1pnu.ua

Tamara Mirkunova, the Department of Business Economics and Investments, Lviv Polytechnic National University, Lviv, Ukraine. Email: tamaramirkunova479@gmail.com

development of exceptionally intelligent society, led to a gradual transformation of the key foundations of the world economics: from consumption to the generation of innovations. The increase of technological intelligence, as the main engine of digitalization, determines their dual nature: on the one hand, such technologies integrate the physical and virtual worlds into single cyberspace, on the other - due to this, they evolve and spread. Digital technology is both a market and a vehicle for the emergence and development of new markets. This creates new challenges to the management of the digital economics and, in particular, the need to develop methodological tools for assessing the cost of innovative technologies in accordance with modern market demands.

According to the Global R\&D Funding Forecast [1, p. 41], Information Technologies (37\%), Software (32\%), Additive Manufacturing (27\%), Big Data (27\%) and Robotics/Automation (26\%) will hold the leading positions in the list of the most important technologies until 2021. The efficiency and success of their commercialization depend on the reasonable economic assessment of these and other innovative technologies that arise and develop on the principles of digitalization. In turn, this is a prerequisite for the competitive development of industries, regions and the country as a whole, contributes to the progress of the digital economics.

Modern methods and models of evaluation should take into account market features caused by digitalization (significant level of convergence and spillover effects from innovative technologies, speed and peculiarities of diffusion of innovations, market susceptibility to new technologies, multiplication effects from them, etc.), be flexible, give effective responses to manage the transfer and commercialization of innovative technologies. There is a need to develop methods for assessing the cost of innovative technologies, which, unlike those already created, would not only take into account the evaluation as such but would also provide various explications of such an assessment.

\section{ANALYSIS OF RECENT RESEARCHES AND PUBLICATIONS}

Evaluation of innovative technologies is impartially a complex issue, and when it comes to technology with a high level of intelligence, estimators face many difficulties of both methodological and institutional nature. However, the 
number and diversity of scientific and applied developments devoted to this topic indicate its relevance, scientific and practical importance.

Mainly, scientists consider the evaluation of innovative technologies within the problem of assessing the effectiveness of innovations as the basis for making appropriate management decisions - V. Dewangan, M. Godse [2], L. Mendes Luz, A. Carlos de Francisco, C. Piekarski [3], M.W. Raja, S. Wei [4]. Some scientists cover the aspects of innovation evaluation within the topic of patent value management $-\mathrm{H}$. Ernst, G. Conley, N. Omland [5], S. Roper, N. Hewitt-Dundas [6], C. L. Benson, C. L. technologies to be evaluated, in particular in the context of digitalization of the economics and the transformation of the role of innovation value are given in works by scientists $\mathrm{R}$. Kamasak [8], S. Muegge [9]. Methodological approaches to the economic evaluation of innovations are revealed in works H. Tohidi, M. Jabbari [10], V. Kozyk, O. Mrykhina, I. Novakivsky, O. Koleshchuk [11]. There is a number of works in which the authors point to the importance of assessing the cost of innovative technologies from the standpoint of economic activities, in particular A. Ayob, A. Hussain, M. Mustaffa, R. Majidc [12], O. Mrykhina [13], others - from the standpoint of preparation and implementation of transfer and commercialization of technologies - S. Kumar, S. Luthra, A. Haleem, S. K. Mangla, D. Garg [14], V. Lesinskyi, O. Yemelyanov, O. Zarytska, A.Symak, O. Koleshchuk [15]. Methodological developments that allow solving some problems of the evaluation of innovative technologies are highlighted in the works Yu. Hubar [16], C. Yang, Q. Zhang, S. Ding [17].

Despite a significant number of developments in the field of evaluation of innovative technologies, not a single methodology that would meet modern market demands has yet been developed. Fragmentariness of developments does not allow for a holistic assessment of the cost of innovative technologies and take into account the features and challenges of the digital economics.

\section{STATEMENT OF PURPOSE}

The purpose of this study is to substantiate the method of evaluation the cost of innovative technologies in the digital economics.

The object of the work is the process of assessing the cost of innovative technologies, the subject - theoretical, methodological and applied foundations of evaluation of innovative technologies in conditions of the digital economics.

\section{RESULT AND DISCUSSION}

Determining the costs of an innovative technology is fairly considered a task of double complexity: it is necessary to find a compromise between the lowest possible price for which the consumer (manufacturer, investor) is willing to buy this technology and the highest possible - for which the seller (developer) is willing to sell it. Along with this, the evaluator faces the problem of finding data and the adequate application of methods of their processing, because the technology is innovative. Magee [7]. Important characteristics of innovative

There is a number of guidelines for the evaluation of innovative technologies - [18-20], which propose parameters of the economic evaluation of innovations. However, they determine the generalized characteristics of the development of innovative technologies, do not provide an opportunity to justify the methodological tools for evaluation, in particular, taking into account the characteristics of the digital economics.

Generally, there are three approaches to the evaluation of the product in the world: profitable, costs, comparative. Among the most common approaches to assessing the value of innovative technologies consider comparative. The object of evaluation is compared with other similar objects of the market or by individual characteristics of these objects that suit the innovative technology.

The study, the results of which are presented in this article, was conducted in the field of industrial electronics in Ukraine (for example, LLC "Diada Group", Kyiv), thus the basis is a legal document - the Methodology for Assessing Property Laws of Intellectual Property, approved by the Order of the State Property Fund of Ukraine [21] (hereinafter - the Methodology).

In the indicated document noted that the cost of innovative technology is determined by adjusting the sale prices (offers) of similar objects arising from the contracts, the essential terms of which meet or will meet the conditions for determining market value.

Therefore, the further course and results of the evaluation will depend on the base chosen for comparison. According to the Methodology [21], the determination of market value using a comparative valuation approach includes the following basic procedures:

- determination of elements as essential characteristics and properties by which the object of evaluation is compared with similar objects (hereinafter-comparison elements);

- determination for each of the comparison elements of the nature and degree of differences of each similar object from the object of evaluation;

- determination for each of the comparison elements of the value of the price adjustment of similar objects, corresponding to the nature and degree of differences of each such object from the object of evaluation for each comparison element;

- adjustment for each of the elements of the price comparison of each such object in order to reduce their differences from the object of evaluation;

- calculation of the market value of property rights of intellectual property by a reasonable generalization of the adjusted prices of similar objects.

The advantage of the comparative valuation approach is the relative simplicity and flexibility in use, a significant disadvantage is the subjectivity of evaluators. Comparative methods are mainly used in a developed market of innovatively active business entities, which operates on the concept of open innovation. Nonetheless, even the methods of the comparative valuation approach require the operation of as clear and accurate estimates as possible, which 

approach.

Using a comparative valuation approach, it is important to have reliable data on prices and other conditions of objects-analogs, the validity of their selection, taking into account the mutual dependence between the factors by which they are compared, etc.

To do this, adjustment is often used. Its essence lies in the fact that it is necessary to analyze the similarities and differences between the objects of evaluation, formalizing their values into the appropriate correction factors that will be used to establish the value of the desired indicator.

According to the Methodology [21], the following valuation procedures can be used to determine the amount of price adjustment for such objects:

- direct comparison in pairs of prices for similar objects differing from each other only by one element of comparison, with the subsequent determination on the basis of the information thus obtained of the amount of money by which the price of such an object is adjusted for this element of comparison;

- direct comparison in pairs of income from the use of two similar objects that differ from each other only by one comparison element, followed by the determination by capitalizing the difference in income of the amount of money by which the price of a similar object is adjusted for this comparison element;

- determination of the costs associated with proof of the characteristics of the comparison element on which such an object differs from the object of evaluation to a state in which there will be no such difference;

- determination of the value of the price adjustment for such objects, indicating in the property rights assessment report the justification of the nature and size of such adjustment.

Using a comparative valuation approach, it is important to distribute the evaluation as a system, into separate subsystems, which will serve to better structure and simplify the problem.

In practice, during the determination of the cost of innovative technologies, it is quite difficult to establish the size of the cost of objects-analogs, but it is possible to know the market prices, from which you can move to the cost of the analyzed technology. So, according to the comparative approach, the price of the estimated technology can be determined at the price level of its analogs on various grounds, namely:

$$
P_{\text {int }}=P_{a}+\sum_{j=1}^{m} \Delta P_{a j}
$$

where: $P_{\text {int }}$ - price of innovative technology, border units; $P_{a}-$ the sale price of similar technology, border units; $m-$ the number of features for comparison; $\Delta P_{a j}$ - correction in the price $(+,-)$ of the sale of a similar technology, according to the $\mathrm{j}$-feature of comparison.

It should be noted that for the evaluation of the comparative approach it is necessary that the number of selected objects-analogs was more than one of the number of correction factors, that is, $\mathrm{n}=\mathrm{k}+1$, where $\mathrm{n}$ - the number of objects-analogs; $\mathrm{k}$ - the number of correction factors. necessitates the formalization of methods within this

In accordance with the equation (1), the evaluation object is compared with each of the selected analog objects, which allows forming a system of linear equations (this approach is developed in $[13,16])$, namely:

$$
\left\{\begin{array}{l}
P_{\text {int }}=P_{1}+\Delta P_{11}+\Delta P_{12}+\ldots+\Delta P_{1 n} \\
P_{\text {int }}=P_{2}+\Delta P_{21}+\Delta P_{22}+\ldots+\Delta P_{2 n} \\
\cdots \ldots \ldots \ldots \ldots \ldots \ldots \ldots \ldots \ldots \\
P_{\text {int }}=P_{m}+\Delta P_{m 1}+\Delta P_{m 2}+\ldots+\Delta P_{m n}
\end{array}\right.
$$

Take into consideration that $\Delta P_{a j}$ depends on the differences in the $\mathrm{j}$-pricing factor between the object of evaluation and the a-analog, so the adjustment is defined as follows:

$$
\Delta P_{a j}=\left(x_{0 j}-x_{a j}\right) \Delta P_{j}=\Delta x_{a j} \cdot \Delta P_{j}
$$

where: $x_{0 j}$ - the value of $\mathrm{j}$-that coefficient of correction for the object of estimation; $x_{a j}$ - the value of $\mathrm{j}$-that coefficient of correction for a-analog; $\Delta P_{j}$ - contribution to unit price of $\mathrm{j}$-that coefficient of correction. Taking into account (3), we write the system (2) as follows:

$$
\left\{\begin{array}{l}
P_{\text {int }}=P_{1}+\Delta x_{11} \cdot \Delta P_{1}+\Delta x_{12} \cdot \Delta P_{2}+\ldots+\Delta x_{1 n} \cdot \Delta P_{n} \\
P_{\text {int }}=P_{2}+\Delta x_{21} \cdot \Delta P_{1}+\Delta x_{22} \cdot \Delta P_{2}+\ldots+\Delta x_{2 n} \cdot \Delta P_{n} \\
\ldots \ldots \ldots \ldots \ldots \ldots \ldots \ldots \ldots \ldots \ldots \\
P_{\text {int }}=P_{m}+\Delta x_{m 1} \cdot \Delta P_{1}+\Delta x_{m 2} \cdot \Delta P_{2}+\ldots+\Delta x_{m n} \cdot \Delta P_{n}
\end{array}\right.
$$

In this system, the unknown values are $P_{\text {int }}$ and $\Delta P_{j}(j=1$, k). The system (4) will be the following:

$$
\left\{\begin{array}{l}
P_{\text {int }}-\Delta x_{11} \cdot \Delta P_{1}+\Delta x_{12} \cdot \Delta P_{2}+\ldots+\Delta x_{1 n} \cdot \Delta P_{n} \\
P_{\text {int }}-\Delta x_{21} \cdot \Delta P_{1}+\Delta x_{22} \cdot \Delta P_{2}+\ldots+\Delta x_{2 n} \cdot \Delta P_{n} \\
\ldots \ldots \ldots \ldots \ldots \ldots \ldots \ldots \ldots \ldots \ldots \\
P_{\text {int }}-\Delta x_{m 1} \cdot \Delta P_{1}+\Delta x_{m 2} \cdot \Delta P_{2}+\ldots+\Delta x_{m n} \cdot \Delta P_{n}
\end{array}\right.
$$

For the convenience of the further decision of system (5), it is expedient to write down it a form of a matrix:

$$
\begin{aligned}
& \Delta X P^{\prime}=P, \\
& P^{\prime}=\left\{\begin{array}{l}
P_{\text {int }} \\
\Delta P_{1} \\
\ldots \\
P_{m}
\end{array}\right\}, \\
& P=\left\{\begin{array}{l}
P_{1} \\
P_{2} \\
\cdots \\
P_{m}
\end{array}\right\} .
\end{aligned}
$$

Solution (8) exists when the determinant of the matrix does not equal zero. Thus, the system has one solution:

$$
P=\Delta X^{-1} P
$$

where $\Delta X^{-1}$ is the inverse matrix to the $\Delta X$ matrix. 
In practice, the factors by which the evaluator compares objects-analogs are mostly qualitative, there is much less opportunity to collect quantitative data. Depending on the scale of assessments, expert assessments can provide a more or less informative amount of data and be characterized by different degrees of mathematical formalization. The choice of a particular gradation for evaluation is determined by previously analyzing the availability of data regarding the evaluated feature and the purpose of evaluation.

We have formed a gradation of qualitative estimates of the factors influencing the formation of the price of innovative technology since such a gradation makes it possible to consider in detail and take into account the differences between the objects of evaluation (Table-I).

Table-I: Gradation of qualitative assessments of factors influencing price formation

\begin{tabular}{|c|c|}
\hline $\begin{array}{c}\text { Gradation of estimates } \\
\text { of factors of influence }\end{array}$ & $\begin{array}{c}\text { The value of the factor } \\
\text { in the range of } \mathbf{1 . . . 1 0}\end{array}$ \\
\hline The weakest influence & $1,0-1,9$ \\
\hline Weak influence & $2,0-3,9$ \\
\hline
\end{tabular}

\begin{tabular}{|l|l|}
\hline Average influence & $4,0-5,9$ \\
\hline Strong influence & $6,0-7,9$ \\
\hline The strongest influence & $8,0-10,0$ \\
\hline
\end{tabular}

For the formation of the price of a set of devices of smooth start, protection and braking of three-phase asynchronous electric motors of LLC "Diada Group" nine objects-analogs were selected and market factors, which influence the pricing for this production, were substantiated. Experts assessed the impact of factors on technology prices (taking into account the mutual correlation of factors) on the basis of the developed in Table-I gradation.

15 experts from the subject area participated in the work, whose opinions were tested for consistency using the concordance factor. The collected expert estimates are reduced to the average estimate for the group by the method of the arithmetic mean.

The results of expert evaluation and market prices of analogs of the analyzed technology are presented in Table-II

Table-II: Indicators of factors influencing the price formation of innovative products (technologies)

\begin{tabular}{|c|c|c|c|c|c|c|c|c|c|}
\hline \multirow[b]{2}{*}{$\begin{array}{l}\text { Names of brands, companies that } \\
\text { sell similar objects }{ }^{*}\end{array}$} & \multicolumn{8}{|c|}{ The factors influencing the formation of prices } & \multirow[b]{2}{*}{$\begin{array}{l}\text { Price, } \\
\text { thousands } \\
\text { UAH }\end{array}$} \\
\hline & 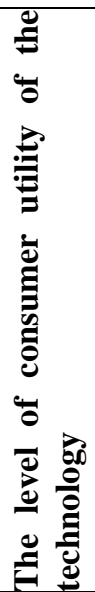 & 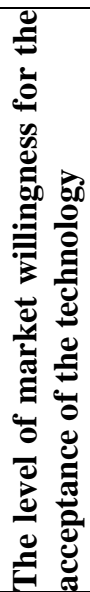 & 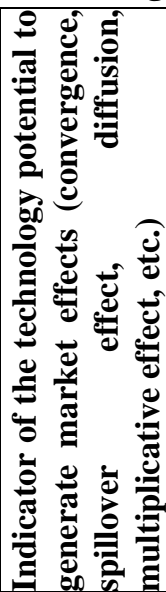 & 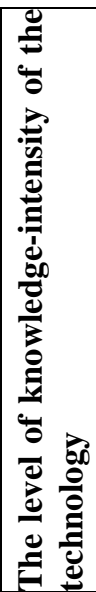 &  &  &  & 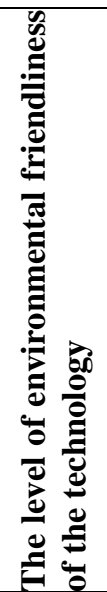 & \\
\hline $\begin{array}{l}\text { The technology of soft start LLC } \\
\text { "Diada Group" }\end{array}$ & 9,5 & 7,6 & 3,7 & 8,7 & 5,3 & 6,1 & 2,0 & 6,0 & - \\
\hline Siemens & 9,7 & 9,2 & 7,0 & 9,5 & 9,2 & 9,8 & 7,8 & 5,6 & 97,020 \\
\hline Carlo Gavazzi & 8,7 & 7,1 & 2,5 & 4,2 & 4.5 & 4,9 & 3,5 & 6,2 & 85,00 \\
\hline Danfoss & 4,2 & 5,1 & 2,1 & 6,2 & 4,1 & 4,5 & 5,5 & 5,3 & 121,00 \\
\hline Samsung & 9,3 & 9,0 & 8,1 & 9,1 & 8,9 & 9,6 & 7,3 & 4,5 & 110,48 \\
\hline Powtran & 3,9 & 1,9 & 1,5 & 4,5 & 3,7 & 1,8 & 2,1 & 1,5 & 67,00 \\
\hline $\mathrm{ABB}$ & 7,7 & 6,9 & 2,5 & 4,2 & 5,1 & 4,9 & 3,2 & 6,1 & 89,34 \\
\hline SV Altera (1) & 4,2 & 4,6 & 2,7 & 6,1 & 6,3 & 7,5 & 5,6 & 6,1 & 60,2 \\
\hline LLC «NPF Oberon» & 5,8 & 5,8 & 1,3 & 4,3 & 4,1 & 5,7 & 1,8 & 2,1 & 71,6 \\
\hline SV Altera (2) & 4,8 & 4,2 & 1,6 & 4,1 & 5,7 & 5,7 & 3,1 & 4,0 & 69,5 \\
\hline
\end{tabular}

*The table shows the names of brands and enterprises, information about technologies (products) which is taken from the sources of open access on the Internet. The received estimates are generalized and can be changed on the basis of the specification of technological and other characteristics of production.

On the basis of Table-II data, the matrixes $\Delta X$ and $P$ are formed: 


$$
\Delta X=\left\{\begin{array}{ccccccccc}
1 & 0.2 & 1.6 & 3.3 & 0.8 & 3.9 & 3.7 & 5.8 & -0.4 \\
1 & -0.8 & -0.5 & -1.2 & -4.5 & -0.8 & -1.2 & 1.5 & 0.2 \\
1 & -5.3 & -2.5 & -1.6 & -2.5 & -1.2 & -1.6 & 3.5 & -0.7 \\
1 & 0.2 & 1.4 & 4.4 & 0.4 & 3.6 & 3.5 & 5.3 & -1.5 \\
1 & -5.6 & -5.7 & -2.2 & -4.2 & -1.6 & -4.3 & 0.1 & -4.5 \\
1 & -1.8 & -0.7 & -1.2 & -4.5 & -0.2 & -1.2 & 1.2 & 0.1 \\
1 & -5.3 & -3.0 & -1.0 & -2.6 & 1.0 & 1.4 & 3.6 & 0.1 \\
1 & -3.7 & -1.8 & -2.4 & -4.4 & -1.2 & -0.4 & -0.2 & 1.5 \\
1 & -4.7 & -3.4 & -2.1 & -4.6 & 0.4 & -0.4 & 1.1 & 2.0
\end{array}\right\} P=\left\{\begin{array}{l}
87.02 \\
81.0 \\
93.0 \\
95.48 \\
69.0 \\
72.34 \\
64.2 \\
70.6 \\
57.7
\end{array}\right\}
$$

and also applying the software package MATLAB, the inverse matrix to $\Delta X^{1}, \Delta X$ is calculated:

$$
\Delta X^{-1}=\left\{\begin{array}{ccccccccc}
2,2371 & 0,2640 & -0,1289 & -0,9995 & 0,8988 & -1,5582 & -1,4216 & 2,0033 & -0,2951 \\
0,2716 & 0,6040 & -0,2825 & -0,2440 & 0,1662 & -0,4780 & 0,1381 & -0,0414 & -01314 \\
-0,0444 & -0,4512 & 0,5080 & 0,1294 & -0,3498 & 0,2986 & -0,6662 & 0,0674 & 0,5080 \\
-0,6645 & -0,2275 & -0,1612 & 0,6126 & 0,0962 & 0,4909 & 0,4044 & -0,0493 & -0,5016 \\
0,5705 & -0,0730 & 0,0676 & -0,3554 & 0,1874 & -0,3607 & -0,2710 & 0,3236 & -0,0891 \\
0,3955 & -0,6777 & -0,2898 & -0,3956 & 0,1348 & 1,0132 & 0,2043 & 0,2248 & -0,1598 \\
-0,1432 & 0,4998 & 0,0642 & 0,2070 & -0,2031 & -0,9333 & -0,1565 & 0,2067 & 0,4584 \\
-0,0854 & 0,3226 & 0,1101 & -0,0280 & -0,0965 & -0,0784 & 0,2279 & -0,3593 & -0,0130 \\
0,0022 & -0,1716 & -0,2608 & -0,1078 & 0,1357 & 0,4968 & 0,4933 & 0,0078 & -0,5955
\end{array}\right\} .
$$

Using the results obtained the elements of the $P_{\text {int }}$ matrix are calculated using the equations (7-8):

$$
P^{\prime}=\left\{\begin{array}{l}
P_{\text {int }} \\
\Delta P_{1} \\
\Delta P_{2} \\
\Delta P_{3} \\
\Delta P_{4} \\
\Delta P_{5} \\
\Delta P_{6} \\
\Delta P_{7} \\
\Delta P_{8}
\end{array}\right\}=\left\{\begin{array}{l}
85,6094 \\
-3,3115 \\
12,8777 \\
-1,9625 \\
1,9030 \\
-16,1928 \\
7,6839 \\
2,5493 \\
-10,8448
\end{array}\right\}
$$

The element $P_{\text {int }}$ is the average market price of the valuated item. Calculations have shown that taking into account the relevant market conditions and aggregating them, in the analyzed period on the device of the smooth start of LLC "Diada Group" it is possible to set the price of 85,6 thousand UAH. This is a price that takes into account the characteristics of the market, the behavior of its consumers at a particular time.

Other elements of the resulting matrix for the soft-start device show the price adjustment, according to the economic value of the influence factor (Table-III).
Table-III: Economic interpretation of the results of the assessment of factors influencing the formation of prices of innovative technology

\begin{tabular}{|l|l|}
\hline Factors & Economic interpretation of the indicator, unit of measurement \\
\hline$\Delta P_{1}$ & $\begin{array}{l}\text { The value of price adjustment depending on changes in } \\
\text { consumer utility of innovative technology, thousand UAH. }\end{array}$ \\
\hline$\Delta P_{2}$ & $\begin{array}{l}\text { The value of price adjustment depending on changes in market } \\
\text { susceptibility of innovative technology, thousand UAH. }\end{array}$ \\
\hline$\Delta P_{3}$ & $\begin{array}{l}\text { The value of the price adjustment, depending on the change in } \\
\text { the potential of innovative technology to generate market } \\
\text { effects, thousand UAH. }\end{array}$ \\
\hline$\Delta P_{4}$ & $\begin{array}{l}\text { The value of the price adjustment depending on changes in the } \\
\text { knowledge intensity of innovative technology, thousand uah. }\end{array}$ \\
\hline$\Delta P_{5}$ & $\begin{array}{l}\text { The value of price adjustment depending on changes in the } \\
\text { competitiveness of innovative technology, thousand ua }\end{array}$ \\
\hline$\Delta P_{6}$ & $\begin{array}{l}\text { The value of price adjustment depending on changes in the level } \\
\text { of the legal protection of innovative technology, thousand UAH. }\end{array}$ \\
\hline$\Delta P_{7}$ & $\begin{array}{l}\text { The value of price adjustment depending on changes in the } \\
\text { social impact of innovative technology, thousand UAH. }\end{array}$ \\
\hline$\Delta P_{8}$ & $\begin{array}{l}\text { The value of price adjustment depending on changes in the level } \\
\text { of environmental friendliness of innovative technology, } \\
\text { thousand UAH. }\end{array}$ \\
\hline$\Delta P_{9}$ & $\begin{array}{l}\text { The value of price adjustment depending on changes in } \\
\text { consumer utility of innovative technology, thousand UAH. }\end{array}$ \\
\hline
\end{tabular}

Thus, considering the estimated market situation:

- the level of consumer utility of the soft-start device has a downward character; due to this factor, the price of the device is reduced by 3,31 thousand $\mathrm{UAH}$;

- the level of market susceptibility of the device tends to increase; due to this factor, the price of the device was increased by 12.87 thousand UAH;

- for the level of potential generation device soft start market effects is characterized by a decrease; due to this factor, the price of the device was reduced by 1.96 thousand $\mathrm{UAH}$; 
the level of knowledge-intensity of soft start technology tends to increase; due to this factor, the price of the device was increased by 1.9 thousand $\mathrm{UAH}$;

- the level of competitiveness of the device has a downward character; due to this factor, the price of the device was reduced by 16,19 thousand $\mathrm{UAH}$;

- the level of protection of the soft-start device tends to increase; due to this factor, the price of the device was increased by 7.68 thousand UAH;

- the level of social influence of the device tends to increase; due to this factor, the price of the device was increased by 2,55 thousand $\mathrm{UAH}$;

- the level of environmental friendliness of soft start technology has a downward character; due to this factor, the price of the device was reduced by 10,84 thousand UAH.

To the given interpretation there is a number of additions and remarks, in particular:

- the value of the market price and the indicators with which you can adjust the price are those that are predetermined by the input parameters of the evaluation system, namely, integrate into its composition the influence of all factors taken into account. Therefore, the obtained values are approximate, aimed at helping managers, evaluators, auditors in the process of making decisions on adjusting prices for technology;

- in the example of soft start technology, the obtained values reflect the situation that is typical for this type of technology and its competitors in the analyzed period of time. That is, the trend of development of consumer utility, the potential to generate market effects, competitiveness and environmental friendliness of technology (according to calculations showed a negative value), characteristic at the present time, indicate certain risks that bear for technology designated factors;

- the method does not make it possible to verify the fulfillment of all the conditions necessary for the price of innovative technology to be considered a part of the market, in addition, it does not fully reflect the technical and economic characteristics of analogous objects and requires the collection of a significant amount of data for evaluation.

\section{CONCLUSION}

The article substantiates the method of evaluation of innovative technologies in the framework of a comparative valuation approach, the peculiarity of which is the matrix structure, which contributes to the flexibility of accounting and/or adjustment of factors of influence of the market environment on the technology at a particular time. This allows increasing the efficiency of pricing. The method can be used as a basis to substantiate the pricing strategy of innovative technologies or to make tactical management decisions regarding their market development in the digital economics.

\section{REFERENCES}

1. The Global R\&D Funding Forecast. $R \& D \quad 100$ Conference, Nov. 16-17, 2018, p. 41.

2. V. Dewangan, M. Godse, "Towards a holistic enterprise innovation performance measurement system," Technovation, 34 (9), 2014, pp. 536-545.
3. L. Mendes Luz, A. Carlos de Francisco, C. Piekarski, "Proposed model for assessing the contribution of the indicators obtained from the analysis of life-cycle inventory to the generation of industry innovation," Journal of Cleaner Production, March 2014, Available: https://www.researchgate.net/publication/260750728_Pr oposed_model_for_assessing_the_contribution_of_the_i ndicators obtained from the analysis of life-cycle inv entory_to_the_generation_of_industry_innovation

4. M.W. Raja, S. Wei, "Evaluating innovation performance and quality practices relationship: a review from different industries," TÉKHNE - Rev. Appl. Manag. Stud., 13, 2015, pp. 25-33.

5. H. Ernst, G. Conley, N. Omland, "How to create commercial value from patents: the role of patent management," RD Manag., 46 (S2), 2016, pp. 677-690.

6. S. Roper, N. Hewitt-Dundas, "Knowledge stocks, knowledge flows and innovation: evidence from matched patents and innovation panel data," Res. Policy, 44, 2015, pp. 1327-1340.

7. C. L. Benson, C. L. Magee, Nguyen Tien Huy (Academic Editor), "Quantitative Determination of Technological Improvement from Patent Data," PLoS One. 2015; 10(4): e0121635. Published online 2015 Apr 15. doi: 10.1371/journal.pone.0121635

8. R. Kamasak, "Determinants of innovation performance: a resource-based study," Procedia Social. Behav. Sci., 195 (2015), pp. 330-1337.

9. S. Muegge, "Business Model Discovery by Technology Entrepreneurs," Technology Innovation Management Review, 2(4), 2012. Available: http://doi.org/10.22215/timreview/545

10. H. Tohidi, M. Jabbari, "Providing a framework for measuring innovation within companies," Procedia Technol., 1, 2012, pp. 583-585.

11. V. Kozyk, O. Mrykhina, I. Novakivsky, O. Koleshchuk, "Methodological Principles of Assessing the Level of Technology Readiness for Transfer on the Basis of the Theory of Reliability of Hierarchically Branched Systems," NTI-UkrSURT 2019,Vol. 67, 15 Oct. 2019. Available:

https://www.shs-conferences.org/articles/shsconf/abs/20 19/08/shsconf NTI-UkrSURT2019 01005/shsconf NTIUkrSURT2019_01005.html

12. A. Ayob, A. Hussain, M. Mustaffa, R. Majidc, "Assessment of creativity in electrical engineering," Procedia - Social. Behav. Sci., 60 2012, pp. 463-467.

13. O. Mrykhina, "Transfer of technologies from universities to the business environment: paradigm, concept and toolkit of assessment". Lviv: Lviv Polytechnic Publishing House, 2018, 440 p.

14. S. Kumar, S. Luthra, A. Haleem, S. K. Mangla, D. Garg, "Identification and evaluation of critical factors to technology transfer using AHP approach," International Strategic Management Review, 3, 2015, pp. 24-42.

15. V. Lesinskyi, O. Yemelyanov, O. Zarytska, A. Symak, O. Koleshchuk, "Substantiation of projects that account for risk in the resource-saving technological changes at enterprises," Eastern-European Journal of Enterprise Technologies, 6(1-96), 2018.

16. Yu. Hubar, "Using of multidimensional model of the method of paired sale for research market value of commercial real estate on the level of regional center," ISTCGCAP. 2012; Volume 76, Number 76, 2012, pp. 133 -136 . 
17. C. Yang, Q. Zhang, S. Ding, "An evaluation method for innovation capability based on uncertain linguistic variables," Appl. Math. Comput., 256, 2015, pp. 160-174.

18. OECD/Eurostat, Oslo Manual 2018: Guidelines for Collecting, Reporting and Using Data on Innovation, 4th Edition, The Measurement of Scientific, Technological and Innovation Activities, OECD Publishing, Paris/Eurostat, Luxembourg, 2018. Available: https://doi.org/10.1787/9789264304604-en

19. OECD (2015), Frascati Manual 2015: Guidelines for Collecting and Reporting Data on Research and Experimental Development, The Measurement of Scientific, Technological and Innovation Activities, OECD Publishing, Paris, 2015. Available: https://doi.org/10.1787/9789264239012-en

20. OECD (2015), Canberra Guide 1995: The Measurement of Scientific and Technological Activities Manual on the Measurement of human resources devoted to S\&T "Canberra Manual", OECD Publishing, Paris, 2015. Available:

https://rio.jrc.ec.europa.eu/en/library/canberra-manual

21. Order of the State Property Fund of Ukraine, "On Approval of the Methodology of Evaluation of Intellectual Property Rights,” № 726/15417, June 25, 2008. Available: https://zakon.rada.gov.ua/laws/show/z0726-08

\section{AUTHORS PROFILE}

Victoria Prokhorova - Doctor of Economics, Professor, Head of the Department of Economics and Activities of Economic Entities, Ukrainian Engineering and Pedagogical Academy, Kharkov, Ukraine. Author of more than 300 scientific papers. Scientific interests: investment-innovative activity of enterprises, renovation methods of development, management of financial rehabilitation. Teaches subjects: - crisis management; financial management; basics of the scientific research; business Economics.

ORCID iD: http://orcid.org/0000-0003-2552-2131

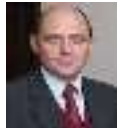

Roman Korzh - Vice-Rector on Scientific and Pedagogical work, Doctor of Engineering, Associate Professor of the Department of Electronics and Information Technology, Lviv Polytechnic National University. Author of more than 80 scientific papers. Scientific interests are concentrated in the field of mathematical modeling of radio-electronic systems and information activities.

\section{ORCID iD: https://orcid.org/0000-0001-8452-0203}

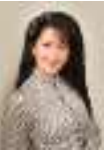

Oleksandra Mrykhina - Doctor of Economics, Professor of the Department of Business Economics and Investments, Lviv Polytechnic National University. She has published more than 120 scientific and methodological works. The main direction of the scientific interests of $\mathrm{O}$. Mrykhina is investmen and innovative activity of the enterprises, transfer of technologies, intellectual capital.

The scientist is a co-editor of the scientific and analytical journal "Our Perspective" (Ukraine) and also reviews articles in scientific and practical journals. O. Mrykhina is the head of research work of Lviv Polytechnic National University: "Theoretical and applied foundations of technology transfer in the systems of strategic development of economic entities" (№ DR 0118U001537, 2018-2023), performs research work on the basis of state budget funding $\mathrm{DB} /$ transfer "Assessment of the cost and readiness of technology transfer from universities to the business environment" (2019-2021). She participated in a number of internships, in particular in the National Academy of Sciences of Ukraine. Works as the expert of the Ministry of Education and Science of Ukraine, the Ministry of Economic Development and Trade of Ukraine.

O. Mrykhina is the developer and teacher of disciplines: "Competitiveness of the enterprise", "Economic diagnostics", "Academic transfer", "Modern technologies of economic research", "Commercialization of innovative projects" and others Actively works with students, the result of which is the recognition of student works at national and international scientific competitions. She was awarded the badge-distinction of the rector of Lviv Polytechnic National University for significant achievements in scientific work (2019).

\section{ORCID iD: https://orcid.org/0000-0002-0567-2995}



Orest Koleshchuk - PhD (Economics), Associate Professor of the Department of Business Economics and Investments, Lviv Polytechnic National University. He has published more than 40 scientific and methodological works. The main area of scientific interest is technology transfer, innovation and innovative susceptibility. O. Koleschuk participates in the research work of the department, manages the execution of the contractual topics. Basic research is related to enterprise innovation management, innovative capacity assessment and susceptibility.

O. Koleschuk teaches the subjects "Economics and Management of Enterprise", "Enterprise Economics", "Fundamentals of Entrepreneurship", "Construction Economics, Fundamentals of Management and Marketing", and others. Supervises the implementation of qualification work by students of the department. Participates in the preparation of student research projects and conferences.

ORCID iD: https://orcid.org/0000-0001-8995-5206

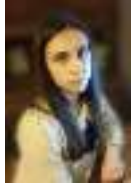

Tamara Mirkunova - a post-graduate student of the Department of Business Economics and Investments, Lviv Polytechnic National University. Mirkunova's main direction of scientific interests is the management of expenses of the enterprises, transfer of technologies of objects of the right of intellectual property. She has published 20 scientific and methodological works.

T. Mirkunova is the executor of research works of Lviv Polytechnic National University: "Justification of innovation and investment strategies, programs and projects for the development of economic structures, industries and regions" (state registration number: 0118U001536) "Economic diagnostics of enterprises, industries and regions in the process of ensuring their sustainable development" (state registration number: 0118U001538). The results of T. Mirkunova's thesis are introduced at Ukrainian enterprises in the field of industrial electronics.

The young scientist took a number of educational courses of Lviv Polytechnic National University to deepen knowledge in the subject area of the thesis.

ORCID iD: https://orcid.org/0000-0003-1772-0445 